\title{
Food security in Sri Lanka - agronomic implications and potentials
}

\author{
U.R. Sangakkara* and S. P. Nissanka \\ Department of Crop Science, Faculty of Agriculture, University of Peradeniya, Peradeniya.
}

\begin{abstract}
The population of the world is growing at an alarming rate and its greatest impact is on the developing nations of Asia and Africa. South Asia, which has the poorest population in Asia is also affected by this process. Among the nations of South Asia, Sri Lanka has a relatively high degree of social welfare, although food security for its 20.1 million people is not achieved. This is due to the phenomenon of smallholder farming systems producing some $90 \%$ of the food required under marginal conditions in low fertile soils. The current problems of irregular climates, global warming and anthropogenic effects of conventional intensive cropping have added to the challenges facing the increase of in-country food production. As land for expansion of food crop cultivation is not available in Sri Lanka, short term measures are required for enhancing crop productivity to ensure food security within the next decade. The options available are breeding suitable crops or enhancing agronomic management of the food crop systems. As breeding programmes take time and could be expensive, the short term measures to increase food production would thus be improved agronomic management of the smallholder farming systems. A principal component of improved agronomic management of food crop systems is the building up of soil quality and its maintenance to ensure sustained productivity in the context of rising costs of inputs. The role of holistic agronomic practices such as green manures, crop rotations, and even agroforestry and their integration to enhance food productivity and maintain sustainability to ensure that Sri Lanka could achieve its targets of food security is presented in this review.
\end{abstract}

Keywords: Agronomy, food security, hunger, integration, soil management.

\section{INTRODUCTION}

'Nutrition is a key element in any strategy to reduce the global burden of disease, hunger, malnutrition, obesity and unsafe food cause disease, and better nutrition will translate into large improvements in health among the populations, irrespective of our wealth and home country.
Thus, food security must be attained for all living beings to sustain the earth and its environments'.

The world's population has grown from 2.5 billion in 1950 to 6.1 billion in 2000, and is projected to rise to 9.1 billion by 2050 , thus clearly indicating a doubling of human numbers over a period of 50 years. It is estimated that over $95 \%$ of the global population increase will take place in the developing world, especially in Africa and Asia, while the developed nations may even show negative growth. Currently the population growth of the world is estimated to be $1.7 \%$, and six nations, of whom five are in Asia, namely China, India, Pakistan, Bangladesh and Indonesia record the highest rates of population ${ }^{2-4}$.

Among the growing population of the world, some 0.85 billion are considered chronically or acutely malnourished. Over $90 \%$ of these are chronically malnourished, while the balance is in acute hunger. Hidden hunger and micronutrient deficiencies affect an additional two billion people and these numbers are increasing ${ }^{5}$. The rapid urbanization taking place in the developing nations, increased incomes of the populations such as in India and China will develop a sustained demand for food, especially for higher value products and for meats and milk. Current estimates indicate that the global demand for rice, wheat and maize will increase by $40 \%$ and for livestock products by $60 \%$ within the next two decades ${ }^{5,6}$.

Food security is a situation in which people do not live in hunger or in fear of starvation. Thus, the Food and Agricultural Organization (FAO) definition for food security states 'Food security exists where all people at all times have access to sufficient, safe and nutritious food to meet their daily dietary needs and food 
preferences for an active and healthy life'. Similarly, the United States Department of Agriculture (USDA) defines food security as follows: 'Food security for a household means access by all people at all times to sufficient food for an active and healthy life. It includes at the minimum the ready availability of nutritionally adequate and safe food and assured ability to acquire acceptable food in socially acceptable ways' ${ }^{7}$. The alternative to food security is food insecurity, which ranges from food security to famine. It is defined as either chronic or transitory. Chronic food insecurity develops into vulnerability and then to hunger and famine, which is found in most developing nations of the world ${ }^{8}$.

Food security has three dimensions, namely a) endemic hunger caused by poverty induced under malnutrition, b) hidden hunger caused by deficiency of micronutrients such as iodine, zinc and Vitamin A in diets, and c) transient hunger caused by natural calamities and civil conflicts. Thus, real food security must not only increase the availability of food for the market but also increase economic, social and physical access to a balanced diet, clean drinking water, environmental hygiene and primary health care. These phenomena are not clearly seen in developing nations ${ }^{9}$, and the UN Millennium Goal to reduce the number of people going to bed hungry by $50 \%$, by the year 2015 , is not being achieved. Hence, food security is a growing problem in all developing nations including South East and South Asia, where nearly $50 \%$ of the world's poor live and where some $70 \%$ of the population lives on less than 2 US\$ per day ${ }^{10}$. The problem is more acute in South Asia where Sri Lanka is situated, which is the home to some $44 \%$ of the world's poor and $40 \%$ of all food insecure people of the world ${ }^{11}$.

\section{Agriculture and food security in Sri Lanka}

Sri Lanka, the pearl of the Indian Ocean is an island of $65,525 \mathrm{sq}$. $\mathrm{km}$ and home to 20.1 million people. It is blessed with a wide range of climates and seasons due to its terrain and abundant rainfall. The soil resources vary by region and thus by cropping systems, forest types and natural vegetation. These bioresource bases lead to a rich natural endowment of biodiversity and this determines the food security and influences on the lives of the Sri Lankan people. Thus, Sri Lanka is an agricultural country where some $60 \%$ of its population is involved in some form of food production or processing ${ }^{12}$.

Sri Lanka has a rich history of placing a high value on basic human needs, thus channeling assistance and subsidies to the rural areas, which consist of small farms responsible for producing $90 \%$ of the food requirements of its population. These measures have been taken by

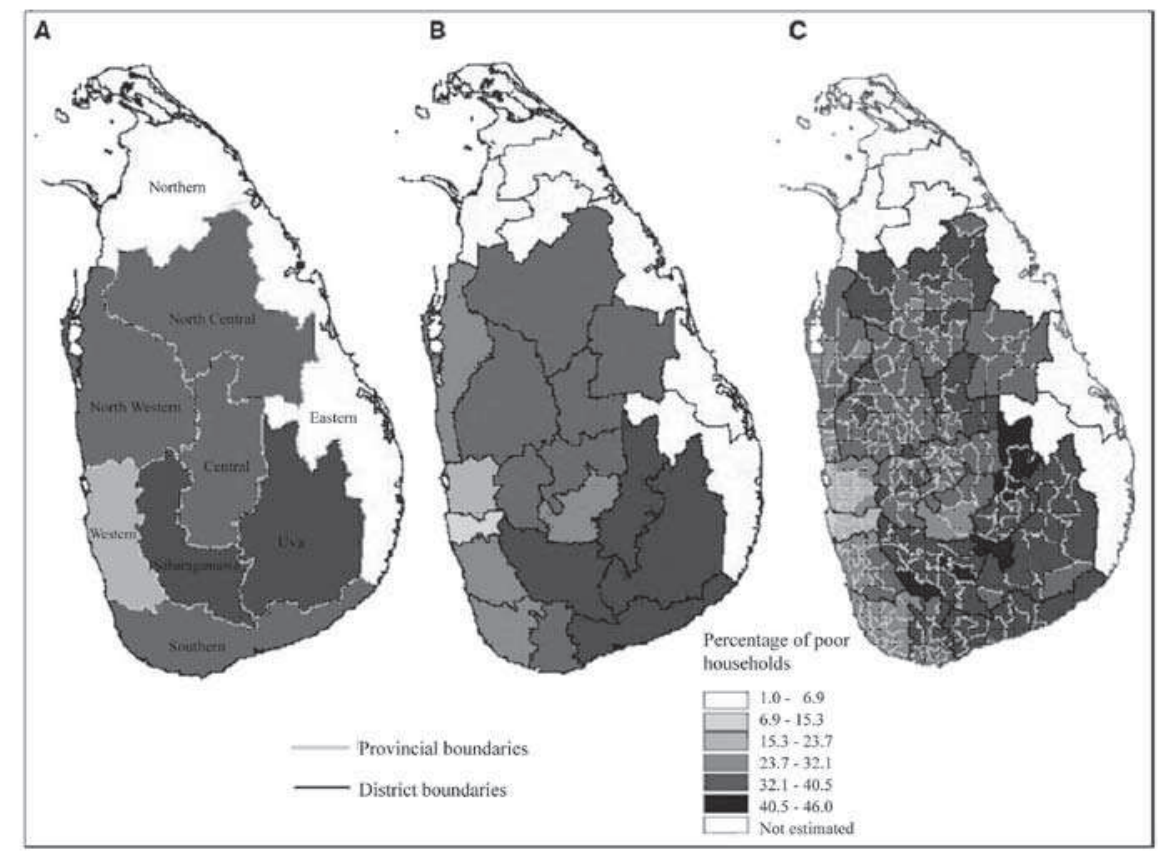

Figure 1: Spatial variation of percentage of poor households across (A) Provincial (B) District and (C) Secretarial divisions of Sri Lanka ${ }^{13}$ 
successive governments to provide food security for the nation and offer employment, while attempting to ensure that people, especially the poor, have access to primary health care, adequate food and basic education. Thus, the nation has achieved significant advances in some areas of human welfare when compared to other low income countries of the region and the world ${ }^{13}$. However, approximately $25 \%$ of the population of the nation still remain below the official poverty line ${ }^{14}$, and the majority of these people live in the rural regions (Figure 1) ${ }^{13}$.

The agricultural sector of Sri Lanka, like in most developing nations, is crop based ${ }^{15}$, and is the primary source of employment to the rural populations. It accounts for $18 \%$ of the GDP, and $60 \%$ of the population largely depends upon this component for their livelihood. It also provides employment directly to $32 \%$ of the population. Furthermore the agricultural sector is principally crop based, which consists of the plantation and non plantation sectors. While the plantation sector provides some 1.5 million people employment, it contributes to $15-16 \%$ of the agricultural GDP. In contrast, the non plantation or domestic food production sector produces food for the people and hence has a direct bearing on food security. The sector is dominated by the rice crop and smallholdings, where over $70 \%$ of the farmer holdings are less than $1 \mathrm{ha}^{16}$, and today over $90 \%$ of the country's food requirements are met by this sector ${ }^{17}$. The other subsidiary food crops consisting of tubers, spices and condiments, vegetables and fruits are also produced in smallholdings, and they do suffer competition from cheaper prices offered to these same commodities from neighbouring nations such as India and Pakistan. Hence, food production in the country has been stagnant over the last decade ${ }^{16}$. Moreover, the agricultural economy of Sri Lanka is struggling to gather momentum to provide larger quantities of food for the nation and also to generate employment, despite the allocation of substantial resources to agriculture and agricultural infrastructure, and for implementation policies such as the Structural Adjustment Policy ${ }^{18}$. Yet for all the agricultural sector of Sri Lanka has not increased its food supply potential over the last few years ${ }^{16}$.

Sri Lanka has made significant advances over its neighbours in South Asia and also over most other countries with comparable or even higher per capita incomes in terms of many social indicators such as literacy levels, infant mortality and life expectancy. However, food insecurity is still a major problem at household levels in Sri Lanka, where the average dietary intake of energy is below the minimum level of 2200 cal per day. Furthermore, reports ${ }^{12,16}$ have indicated that some $37 \%$ of men and $33 \%$ of women suffer from chronic energy deficiency, while $33 \%$ of children below 5 years of age are malnourished, and $13 \%$ of this number is acutely affected. These inadequacies are concentrated among the poor and people displaced by the civil strife which has plagued the nation for over two decades. The rural poor in the dry regions where irrigation facilities are not available (i.e. the remote regions of Moneragala in Uva and the Anamaduwa regions of the North Western provinces) suffer from food insecurity, and recent estimates suggest that their energy intake is some $60 \%$ of the daily needs. Thus, food security or insecurity is of significant concern to the Government of Sri Lanka and although many agencies, both governmental and non governmental, attempt to solve it through different programmes and activities, the process poses a major challenge ${ }^{18}$.

\section{Problems of food supply in Sri Lanka}

When compared to the plantation sector, small farmers of the food crops sector are an integral part of South Asian and Sri Lankan Agriculture ${ }^{19}$. They are characterized by a high degree of diversity and complexity and the farmers live in the shadows of poverty and hence of food insecurity, in contrast to most farming communities of the developed world. In Sri Lanka, while most rice farmers in the major producing regions where irrigation is available have benefited by the very recent fertilizer subsidies, and the intensive vegetable farmers in the hilly regions have made profits and reaped benefits from cropping enterprises, other minor food crop sectors, especially in the rural regions face many difficulties. Among the many problems faced by these rural farmers who grow food crops under difficult conditions, attention should be directed towards features such as soil degradation caused through improper land use and erosion, intensive cropping to grow some crops for food and sale without paying heed to soils quality through the addition of organic matter during the seasons and in interseasonal periods, lack of infrastructure such as irrigation, low input use, low economic efficiency and poor managerial strategies ${ }^{19}$. Furthermore, these farmers are resource poor people living and working in harsh or less fertile environments. Farmers in these rural regions also have little access to major decision making processes and new technologies, although most have secured tenure through different laws implemented by the successive governments over the years since independence. They also have the capacity to adapt and survive hardships and use the meager resources judiciously. However, the problems of food production by these farmers do not 
end with these conditions. The problems in contrast are further compounded by the phenomena of not having access to good planting material, duties imposed upon inputs (except fertilizers for rice), high labour costs in comparison to those of India and Pakistan, and post harvest losses due to improper harvesting, packaging, transport and storage. All these and the present increasing costs of all commodities along with the fluctuations of exchange rates and inflationary trends compound the problems of food production and food security in Sri Lanka ${ }^{16,20,21}$. Amidst all these problems faced by farmers, global changes and problems would also affect the food production sector of Sri Lanka. Experts are becoming increasingly concerned about the implications of climate changes as a long term threat to agriculture and food security ${ }^{22}$. The general consensus is that changes in climatic conditions will affect agricultural productivity, especially that of food crops, and qualitative evidence indicate that developing countries near the lower latitudes such as Sri Lanka will especially be vulnerable to changes in the environment due to climate changes $^{23,24}$. This is further compounded by reports ${ }^{25}$ which show that the two major tropical cereals are more vulnerable to global warming than temperate cereals (Figure 2). The predicted changes in temperatures of Sri Lanka for the next 50 years ${ }^{26}$, and its impact on water availability even for rice in the dry zone clearly show greater problems of meeting food demands by the growing populations in the coming years, which
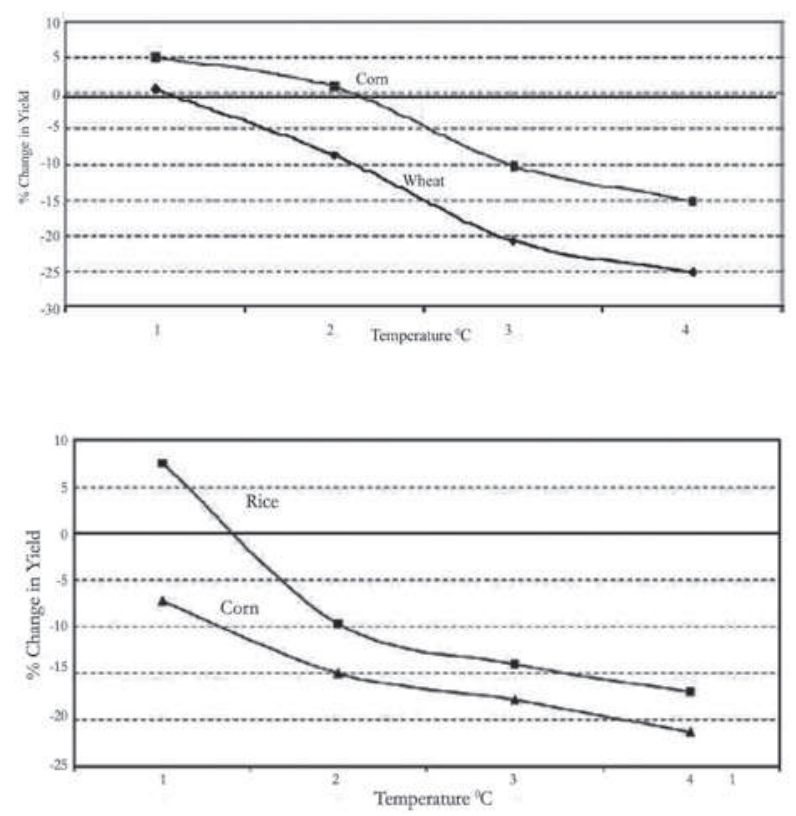

Figure 1: Comparative reduction in yields of corn, rice, and wheat in the tropical and temperate regions as affected by rising temperatures (adapted from reference no. 25) could lead to further increases in food insecurity in Sri Lanka, although studies on modelling ${ }^{23}$ state that the impact of climate change will vary considerably across geographical areas of the nation, from losses of $67 \%$ to gains of more than double the current incomes and revenues. They state that the largest impact are anticipated in the drier regions of the North Central and South Eastern regions of Sri Lanka which produce most of the rice for the nation, while the intermediate and wet zones are likely to benefit due to predicted increments in rainfall.

\section{Agronomic implications for food security}

Agriculture in Sri Lanka is very closely associated and dominated by crops and hence food security is also directly linked to adequate production of crop based commodities for both human and livestock consumption. As in all developing nations, the best land for agriculture in Sri Lanka is under considerable pressure as industrialization and urban sprawling have absorbed arable land from cropping. This is clearly evident in the land development programmes of most cities of the developing world ${ }^{27}$, which is also seen around the cities of Sri Lanka. This means that increasing quantities of food need to be produced from a shrinking land base and from marginal soils of suboptimal lands.

Studies by the FAO highlight three strategies to enhance food security in developing nations. These are increasing crop yields, increasing intensity of cropping and cultivation of new land resources. Thus in 2000, surveys revealed that about $63 \%$ of increase in food production were from yield enhancement, $15 \%$ from increasing cropping intensity and $22 \%$ from cultivating new lands. As the land area for expansion is limited, especially in populous nations of South Asia such as Sri Lanka, with its 20.1 million people in 65,525 sq. km, the short term measures for overcoming food insecurity could be by increasing yields and intensities both on optimal and suboptimal growing conditions ${ }^{28}$.

Recent agricultural programmes in the developing nations of Asia were stimulated by the Green Revolution, which played a key role in achieving national food security and reducing rural poverty. It also prevented deforestation to some extent and reduced the expansion of cropping into environmentally fragile regions. However, the Green Revolution was also destructive in many regions and caused problems of salinity, fertilizer and pesticide contamination, and loss of soil quality in some of the world's most productive lands. The processes of the Green Revolution also lowered water tables in many regions. These problems began in the 1970's and 
evidence shows that yields of major food commodities such as rice peaked and in some instances even declined after a period of time ${ }^{29,30}$. In this scenario in South Asia, including Sri Lanka, the question that arises is - What solution could the farming community be offered to maintain and more importantly enhance food production for food security?

Under conditions of limited and even diminishing resources, crop yields could be enhanced by two options, namely breeding and improved management ${ }^{31}$. The breeding programmes initiated by the Green Revolution, suitable agronomic and fertilizer practices, irrigation and remunerative markets ensured greater harvests. However, the current situation of stagnant rice yields in Sri Lanka after the 1980's with marginal increases, which are below population growth ${ }^{32}$, is attributed to a combination of adverse technological, ecological and marketing factors, which is sometimes referred to as "Fatigue of the Green Revolution" and poses a fresh challenge to the agricultural communities of the developing nations. Hence, attempts need to be made to reverse this declining trend and ensure adequate food to achieve food security ${ }^{9}$.

Conventional plant breeding is a time consuming process and once new crops and varieties are bred or selected, they have to be tested over time and in many locations. The use of genomics in plant improvement has made significant progress. However, reports ${ }^{33}$ state that while the new technology has a significant contribution to make to agriculture of the developing world, the persistence of poverty in these regions demonstrates that their impact has been very low. This is attributed to the high costs of research and also the lack of relevant information on the management practices that is needed to optimize production in the new varieties and cultivars. The fear of genetically modified crops in food systems causing possible unforeseen problems also poses questions and hence it is evident that short term improvement in food security in the developing world can best be achieved by better agronomic methods and crop management to ensure higher and sustainable yields under conditions of diminishing resources.

\section{Agronomic methods to ensure food security}

Small farms are the foundation of the South Asian food crop sector and this phenomenon is true for Sri Lanka. Their role in ensuring food security in the next two decades is of vital importance, and the most suitable options available under the present scenario for reducing food insecurity in the short term are improved methods of crop and even animal management, post harvest techniques and marketing ${ }^{19}$. Furthermore training, education of rural farming communities and infrastructure development will assist in this important venture ${ }^{9}$, although the production capacity of small farms is dependant on proper crop husbandry.

Agronomic techniques required under the present circumstances of the developing world should enhance land, water and labour productivity. Smaller the farm greater is the need for increased productivity and sustainability. This in the present context means, the nurture of the soils in these degraded lands to maintain soil quality and productivity through agronomic means, and the use of integrated and low cost methods. In a comprehensive review ${ }^{34}$, this aspect was considered in detail, and the options available for agronomic regeneration of soil fertility especially in the tropical upland smallholder farms in Asia, with rice systems have been well documented ${ }^{35}$.

Among the most important agronomic methods of maintaining productivity is the maintenance of soil quality and this is achieved through the application of organic matter to the tropical soils. The importance of this aspect cannot be emphasized to any great extent, especially in the context of Africa ${ }^{36}$ that highlights the link between unhealthy people and unhealthy soils, due to the negligence of soil quality. Thus, organic matter and soil conservation measures are key indices of soil quality that need to be maintained because agriculture, especially crop production, has been subjected to anthropogenic influences through intensive and haphazard management, which has caused the degradation of soil and water resources ${ }^{37}$.

The inclusion of organic matter or carbon to soils is best done through plant materials as green manures play a significant role in this context. The green manures can either be ex situ or preferably in situ applications, but its importance in ameliorating soil degradation is a feature that needs to be remembered in maintaining crop productivity and sustenance of soil health and quality on smallholder tropical farming systems. The potential benefits of green manuring could be listed as the improvement of soil physical, chemical and biological properties, and thus crop yields. Green manure also reduces leaching of nitrates, and hence lowers nitrogen fertilizer requirements for succeeding crops. Although the beneficial influences could vary from soil to soil, environmental conditions, green manure types and its management as well as its beneficial effects far exceed that of the difficulties. However, in the context of integrated farming for smallholders who strive to enhance yields on a sustainable basis, their benefits must be viewed in 
terms of their inclusion along with chemical fertilizers ${ }^{38}$. Several studies thus have been quoted ${ }^{34}$, that highlight the benefits of green manures for crop productivity under Sri Lankan conditions.

Sustaining soil fertility in tropical cropping systems through agronomic interventions could also be carried out through systems of mixed cropping, crop rotations, fallow systems, residue management and addition of organic matter from external sources such as composting urban organic wastes ${ }^{19,34,39}$. All these systems have been researched by individuals under diverse environments, and the need today is to develop studies on comparative advantages and benefits of the different systems on an integrated basis. This vital information is currently lacking and hence is of importance in the short term to maintain and possibly increase yields and productivity, while sustaining the smallholder crops based farming systems of Sri Lanka and of other similar nations across the world.

Agroforestry is another aspect of agronomy that has come of age, and today it offers a comprehensive programme to reduce land degradation and provide ecosystem services, especially to low income farmers of the developing world ${ }^{40}$. The combinations of trees and crops in spatial or temporal arrangements have shown the possibilities of enhancing food and nutritional security, while mitigating environmental degradation and offering a sustainable alternative to monocultures across diverse environments and landscapes. It also offers social benefits as well in situations of hazardous and degraded environments, while sequestering carbon which is of importance in today's context of global warming ${ }^{41}$.

The concept of an evergreen revolution ${ }^{9}$ highlights the importance of overcoming the problems of soil fertility caused by the first green revolution and its systems of farming adopted principally by Asia from the late 1960's. The evergreen revolution places emphasis on agronomic methods such as organic farming, green agriculture, eco agriculture, effective micro-organisms agriculture, white agriculture and one straw revolution. In contrast, the second green revolution proposed 42 emphasizes the development of crops and varieties having the potential to produce higher yields in low fertility soils. The argument placed is that these crops would have the potential of improving productivity and sustainability of the low input farms found in the tropics such as in Sri Lanka and other similar nations. This concept is supported by the facts that include the long time lag required to increase soil quality in the tropics, where organic matter degradation is high, the current increasing populations requiring food, on going soil degradation in most smallholder systems, and increasing costs of chemical fertilizers, which will call for crop species and varieties capable of growing and producing food under low fertility conditions. However, the identification and selection of such crops take time, whereas the need is for greater productivity at the present time, and here again the importance of agronomic methods is emphasized.

Maintaining productivity of small farms via the addition of organic matter to soils in tropical Asia could also be carried out successfully by integrating animal husbandry ${ }^{19}$, along with the blending of natural resources. Animal manures offer an effective and efficient method of recycling nutrients as shown by an excellent case study in Thailand ${ }^{43}$. This study clearly highlights the benefits of integrating livestock and aquaculture into rice systems of Northeast Thailand, which out-performed the normal conventional monoculture systems in all dimensions of multifunctional agriculture, namely food security, environmental stability, economic and social functions. Although the integration of all these components may not be possible under conditions of Sri Lanka, such studies could offer significant mechanisms for enhancing productivity of the small farms which produce over $90 \%$ of the food requirements of our nation to develop the possibility of overcoming food insecurity on a sustainable basis. Thus comparative studies along these lines are of vital importance and hence should be considered as a priority in research, development and training programmes in the developing world such as that of Sri Lanka.

The role of biotechnology in overcoming food insecurity in the developing nations has been presented very recently ${ }^{44}$, which highlight the importance of these processes to provide nutritious food to the poor populations. The processes of biofortification of traditional food crops could be used to enrich the diets and thus provide nutritious food. However the role of genetically modified crops in human diets is being debated and hence the acceptance of these crops, which are in the field trial stage is yet to be determined.

\section{CONCLUSION}

Today, food security has become a major issue in the developing world and in Sri Lanka, where the government is trying to provide food for its people in the face of shortages, natural disasters and increasing prices of food commodities in the world market due to many reasons. The problems become greater in areas with degraded lands and in places where land is being degraded. 
Thus, the paradigm shift that nations such as Sri Lanka need to make to sustain food production is to develop holistic and sustainable crop and land management programmes that have been validated in other parts of the world. Research investment must contribute to the development of knowledge on more efficient methods of crop management and more productive means of crop production. The nation and its policy makers must realize that human carrying capacities of land is not only a national problem but also has a global impact, and an active programme should be developed to monitor and assess land degradation, while implementing national and international policies that facilitate access to food through a fair and equitable market system. However among all these, the first step is the development of sound agronomic management of cropping systems and their soils ${ }^{45}$.

Agronomic management of crops begins with the selection of a good site for cropping through to variety and seed selection, land preparation, crop establishment, fertilizer management, weed, pest and disease control, provision of adequate moisture, and special measures such as mulching and harvesting at the correct time. At present, most of these practices are neglected in smallholder cropping programmes. Farmers prepare land haphazardly, use low quality planting material and do not manage crop nutrition optimally, over or under use pesticides, and harvest at times that would bring the highest income, rather than at the proper time of maturity. All these aspects need attention, as proper care for crops and soil would lead to reaping the benefits over a very short period of time in comparison to breeding programmes, that take time and involve high cost genetic research, which is the trend at the present time. If Sri Lanka needs to assure that its people have adequate food, emphasis should be placed to a greater extent on agronomic research that will have short term benefits, and such knowledge needs to be given to the farming community through education and training. It does not mean that nations such as Sri Lanka should give up breeding or genetic research. These are important, although in the short term, if the goal is to obtain greater productivity to ensure food security in a competitive world, where food crops may give way to biofuel crops thus causing food scarcity in the developing nations ${ }^{46}$, greater attention needs to be placed upon agronomic programmes. The threats of the impact of global warming also calls for better management of the existing crops to overcome heat stress and possible scarcities of water. All these clearly illustrate that in the short term food security in Sri Lanka is low with land recources limited for agriculture, high dependency on small farms for providing food in the midst of rural poverty, but can best be achieved via better agronomic management of cropping systems. This would lead to greater yields from existing resources to provide a better nutrition to the peoples of our nation and similar nations of the developing world, thus providing holistic and better standards of living for both urban and rural populations.

\section{Acknowledgement}

The authors are grateful to the facilities provided by the ETH Zurich, Switzerland for compiling this paper

\section{References}

1. WHO (2002). Reducing risks, promoting healthy life. In. : The World Health Report 2002 (Ed. B. Campanini). pp. 1 - 168, World Health Organization, Geneva, Switzerland.

2. Cohen J.E. (2005). Human population grows up. Scientific American (Special issue): $26-33$.

3. U.N. (2005). World Population Prospects: The 2004 Revision Highlights. Population Division, Department of Economic and Social Affairs, United Nations, New York.

4. Carvalho F.P. (2006). Agriculture, pesticides, food security and food safety. Environmental Science and Policy $9(7-8): 685-692$.

5. Zhang W., Bai C. \& Liu G. (2007). A longer term forecast on global supply and demand of food products. Journal of Food, Agriculture \& Environment 5(1) : 105 - 110.

6. Alexandratos N. (1999). World food and agriculture: outlook for the medium and longer term. Proceedings of the National Academy of Science USA 96: 5908 - 5914.

7. www://en-wikipedia.org/wiki/fod_security. Accessed in December 2007.

8. Von Braun J., Swaminathan M.S. \& Rosegrant M.W. (2004). Agriculture, food security, nutrition and the millennium development goals. Annual Report, The International Food Policy Research Institute (IFPRI), Washington DC, USA. www.ifpri.org/pubs/books/ar2003/. Accessed in December 2007.

9. Swaminathan M.S. (2007). Can science and technology feed the world in 2005? Field Crop Research 104 (1-3) : 3 - 9.

10. World Bank (2005). World Development Indicators, World Bank, Washington DC. (CD rom).

11. Chandra Babu S. \& Gulati A. (2005). Economic reforms and food security in South Asia - an overview of the issues and challenges. In: Economic reforms and food security. The impact of trade and technology in South Asia (Eds. S. Chandra Babu \& A. Gulati) pp. 1 - 33, Hawthorn Press, Binghamton, New York.

12. FAO (2005). FAOSTAT, Agriculture. Food and Agriculture Organization, Rome.

13. Amarasinghe U., Samad M. \& Anputhas M. (2005). Spatial clustering of rural poverty and food insecurity in Sri Lanka. Food Policy 30: 493 - 509. 
14. Department of Census and Statistics (2005). Annual Statistics of Sri Lanka. Dept of Census and Statistics, Colombo.

15. Devendra C. (2002). Crop-animal systems in Asia : future perspectives. Agricultural Systems 71: $179-186$.

16. Kelegama J. \& Chandra Babu S. (2005). Market reform, diversification and food security in Sri Lanka. In : The impact of trade and technology in South Asia (Eds. S. Chandra Babu \& A. Gulati). pp 311 - 328. Hawthorn Press, Binghamton, New York.

17. Central Bank (2005). The Annual Report. Central Bank of Sri Lanka, Colombo.

18. Yamaguchi M. \& Sanker S. (2007). Growth accounting for Sri Lanka's agriculture with special reference to fertilizer and non agricultural process: do policy reforms affect agricultural development? The Developing Economies 45: $194-219$.

19. Devendra C. (2007). Small farm systems to feed hungry Asia. Outlook on Agriculture 36: 7 - 20.

20. Sandaratne N. (2000). The Rice Economy: Challenges in the next decade. Inaugural address of the Rice Symposium, December, 2000. University of Peradeniya, Peradeniya.

21. Bamunuarachchi A. (2001). Minimizing of post harvest losses in fruits and vegetables. National Task Force for minimizing of post harvest losses in fruits and vegetables. Ministry of Agriculture, Battaramulla.

22. Intergovermental Panel on Climate Change IPCC (2001). Climate Change 2001. Impacts, Adaptation and Vulnerability. Cambridge University Press, Cambridge, UK.

23. Kurukulasuriya P. \& Ajwad M. I. (2007). Application of the Riocardian technique to estimate the impact of climate change on smallholder farming in Sri Lanka. Climatic Change 81: $39-59$.

24. Ziska L.H. \& Bunce J.A. (2007). Predicting the impact of changing $\mathrm{CO}_{2}$ on crop yields: Some thoughts on food. New Phytologist 175: $607-618$.

25. Easterling W. \& Apps M. (2005). Assessing the consequences of climate change for food and forest resources: A view from the IPCC. Climatic Change 70: 165 - 189.

26. De Silva C.S., Weatherhead E.K: Knox J.W. \& Rodriguez-Diaz J.A. (2007). Predicting the impacts of climate change : a case study of paddy irrigation water requirements in Sri Lanka. Agricultural Water Management 93: 19 - 29.

27. Singh P. (2005). Technology options for achieving food security in South Asia. In : The Impact of Trade and Technology in South Asia (Eds. S. Chandra Babu \& A. Gulati). pp. 163 - 174. Hawthorn Press, Binghamton, New York.

28. Pingali P. \& Rosegrant M.W. (2000). Intensive food systems in Asia: can degradation be reversed? In :Tradeoffs or Synergies? Agricultural Intensification, Economic Development and the Environment. (Eds. D.R. Lee \& C.B. Barret). pp. 383 - 398. CABI, Wallingford, UK.

29. Fan S., Hazell P. \& Haque T. (2000). Targeting public investments by agro ecological zone to achieve growth and poverty alleviation goals. Food Policy 25: $411-428$.

30. Hazell P. (2005). Future challenges for the rural South Asian economy. In : The Impact of Trade and Technology in South Asia (Eds. S. Chandra Babu \& A. Gulati). pp 175 - 186. Hawthorn Press, Binghamton, New York.

31. Van Ginkel M. \& Ogbonnaya F. (2007). Novel genetic diversity from synthetic wheats in breeding cultivars for changing production conditions. Field Crops Research 104: $86-94$.

32. Department of Census and Statistics (2006). Annual Statistics of Sri Lanka. Dept of Census and Statistics of Sri Lanka, Colombo.

33. Reece J.D. \& Haribabu E. (2007). Genes to feed the world: the weakest link? Food Policy 32: $459-479$.

34. De Costa W.A.J.M. \& Sangakkara U.R. (2006). Agronomic regeneration of soil fertility in tropical Asian smallholder uplands for sustainable food production. Journal of Agricultural Science (Cambridge) 144: 111 - 133.

35. Saha P.K., Ishaque M., Saleque M.A., Miah M.A.M., Panaullah G.M. \& Bhuiyan N.I. (2007). Long term integrated nutrient management for rice based cropping pattern: effect on growth, yields, nutrient uptake, nutrient balance sheet and soil fertility. Communications in Soil Science and Plant Analysis 38: 579 - 610.

36. Sanchez P. \& Swaminathan M.S. (2005). Hunger in Africa: The link between unhealthy people and unhealthy soils. The Lancet 365 (9457) : 442 - 444.

37. Lal R. (2007). Anthropogenic influences on world soils and implications to global food security. Advances in Agronomy 93: 69 - 93 .

38. Fageria N.K. (2007). Green manuring in crop production. Journal of Plant Nutrition 30 (5): 691 - 719.

39. GrahamR.D.,WelchR.M., SaundersD.A.,Ortiz-Monasterio I., Bouis H.E., Bonierbale M., de Haan S., Burgos G., Thiele G., Liria R., Meisner C.A., Beebe S.E., Potts M.J., Kadia M., Hobbs P.R., Gupta R.J. \& Twomlow S. (2007). Nutritious subsistence food systems.Advances in Agronomy 92: $1-74$.

40. Nair P.K. R. (2007). The coming of age of agroforestry. Journal of the Science of Food and Agriculture 87: 1613 $-1619$.

41. Nair P. K.R. (2005). Agroforestry: trees in support of sustainable agriculture. In : Encyclopedia of Soils in the Environment. Vol 1. (Eds. H.C. Hille, D. Rosenzweig, K. Powlson, M. Scow, Singer. \& D. Sparks). pp $35-44$. Elsevier, London, UK.

42. Lynch J.P. (2007). Roots of the second green revolution. Australian Journal of Botany 55: 493 - 512.

43. Tipraqsa P., Craswel E., Noble A. \& Schmidt-Vogt D. (2007). Resource integration for multiple benefits: multifunctionality of integrated farming systems in Northeast Thailand. Agricultural Systems 94: 694 - 703.

44. Gilani G.S. \& Nasim A. (2007). Impact of foods nutritionally enhanced through biotechnology in alleviating malnutrition in developing countries. Journal of AOAC International 90: 1440 - 1444.

45. Blum W.E.H. \& Eswaran H. (2004). Soils for sustaining global food production. Journal of Food Science 69: $37-42$.

46. Boddiger D. (2007). Boosting biofuel crops could threaten food security. The Lancet 370: 923 - 924. 